\title{
DIAGNOSIS AND TREATMENT OF AGGRESSIVE PERIODONTITIS
}

\author{
Ricardo Benza-Bedoya ${ }^{1}$, Maria Pareja-Vásquez ${ }^{2}$
}

DOI: 10.22592/o2017n30a4

\begin{abstract}
Aggressive periodontitis is a low-prevalence, multifactorial disease, of rapid progression and with no systemic compromise. It presents immunological alterations, a strong genetic influence, familial aggregation and early onset. It can be localized or generalized. It is not clear whether it is an independent periodontal disease, or if it is the phenotypic expression of chronic periodontitis in susceptible patients. Its diagnostic protocol includes a dental medical history, a clinical periodontal examination and a radiological examination. Treatment usually includes improving oral hygiene, dental scaling and root planing, as well as systemic and local antibiotic therapy. Surgical therapy will depend on each individual case. Maintenance therapy is essential to achieve better results. The aim of this paper is to review diagnostic and therapeutic protocols, and to propose a treatment flowchart based on the latest scientific evidence.
\end{abstract}

Keywords: aggressive periodontitis, diagnosis, therapy, antibacterial agents, microbiology.

${ }^{1}$ Dental Surgeon. Periodontics Specialist. Universidad de San Martín de Porres. Lima, Perú. ORCID: 0000-00025020-3485

2 Associate Professor and Periodontics Specialist. Universidad de San Martín de Porres. Lima, Perú. ORCID: 0000-0002-5497-6231

Received on: 04 Aug 2016 - Accepted on: 10 Jul 2017 


\section{INTRODUCTION}

Aggressive periodontitis is a rare form of periodontal disease, which is characterized by rapid attachment loss, bone destruction, non-contributory medical history and family history of the cases $^{(1,2)}$.

Early identification of this pathology can help prevent early loss of teeth. It is important to ensure appropriate care, prevention, diagnosis and treatment of aggressive periodontitis in health facilities in order to reduce the risk of functional impairment of the stomatognathic system and its systemic impact. It is also a priority to standardize and articulate the procedures provided in all the national healthcare institutions for this pathology.

This paper aims to be an updated review of the literature on diagnostic methods and treatments for aggressive periodontitis according to scientific evidence, which is expected to be useful for general practice dentists and periodontists.

\section{METHOD}

A non-systematic narrative review was conducted regarding the diagnosis and treatment criteria for aggressive periodontitis. The descriptors used were: "aggressive periodontitis", "diagnosis", "treatment", "antibiotics", "Microbiology". Papers in English and Spanish were included. The papers were selected from PubMed, SciELO, Lilacs and Google scholar.

\section{RESULTS}

1. Definition. Aggressive periodontitis is a type of periodontal disease with rapid insertion and alveolar bone loss, which is characterized by familial aggregation and affecting healthy individuals, except periodontitis ${ }^{(3)}$. It usually affects young people, but it can appear at any age, although this is less frequent ${ }^{(3,4)}$.

2. Terminology and classification In 1999, the American Academy of Periodontology (AAP) Workshop coined the term "aggressive periodontitis", and the disease was classified as "localized and generalized"(3,4).

3. Etiology Aggressive periodontitis is a multifactorial and genetically complex disease. An increase in host susceptibility may be caused by the combined effect of genetic 
predisposition, environmental factors (virulent pathogens, tobacco smoking, personal and professional hygiene) and local contributing factors. Furthermore, herpesvirus could be an additional factor of susceptibility and severity in aggressive periodontitis ${ }^{(5)}$.

The generalized form of aggressive periodontitis has been strongly associated with bacteria such as Porphyromonas gingivalis, Agregatibacter actinomycetemcomitans (Aa) and Tannerella forsythia(6,7); recent studies suggest that other microbial species could also be associated $^{(8)}$. In generalized aggressive periodontitis there is an inadequate response to the action of the periodontal pathogenic bacteria caused by a variety of genetic and immunological risk factors ${ }^{(9,10)}$.

Recent findings suggest that the pathogenesis of localized aggressive periodontitis is associated with severe abnormalities in the neutrophil function, producing neutrophil-mediated tissue injury ${ }^{(11)}$. These abnormalities appear to be the result of a stage of chronic hyperactivity of neutrophils; these findings are consistent with recent reports of decreased neutrophil chemotaxis in localized aggressive periodontitis ${ }^{(12,13)}$. Some studies suggest that this is due to abnormalities in the transduction signals. In addition, the neutrophils of patients with localized aggressive periodontitis show reduced calcium entry ${ }^{(14)}$, defective calcium influx factor ${ }^{(15)}$, abnormal activity of protein kinase $\mathrm{C}^{(16)}$, among other abnormalities.

\section{Epidemiology}

The prevalence of aggressive periodontitis is variable. It is estimated that there is a low prevalence (less than 1\%) in Caucasian subjects living in developed countries compared to those living in developing countries $(-0.5 \text { to } 5 \%)^{(17)}$. One aspect that complicates the interpretation of aggressive periodontitis regarding epidemiological information is the parameters used to evaluate the identification of cases, which vary from one study to the other ${ }^{(18,19)}$. Africans and African-Americans seem to have the highest prevalence of aggressive periodontitis: $1.0-3.0 \%$. They are followed by Asians, with $0.4-1.0 \%$, and Hispanics and South Americans, with 0.5-1.0\%, compared to Caucasian young populations, with $0.1-0.2 \%{ }^{(20-22)}$. Löe and Brown estimated that African American adolescents are fifteen 
times more likely to have aggressive periodontitis than white adolescents ${ }^{(23)}$. Kissa et al. found no differences in prevalence by gender and ethnic group ${ }^{(24)}$. Mwokorie and Arowojolu found a prevalence of $1.6 \%$ in a population group whose age ranged from 17 to 34 in a Nigerian hospital(25). Albandar et al. reported high prevalence levels of aggressive periodontitis among Ugandan students aged 12-25; of which $6.5 \%$ showed generalized or localized aggressive periodontitis; and $22 \%$ showed incidental aggressive lesions ${ }^{(26)}$. Hodge et al. suggested that genetic factors are more significant than history of smoking in the manifestation of generalized aggressive periodontitis ${ }^{(27)}$. There are no epidemiological studies related to aggressive periodontitis in Perú.

\section{Risk factors}

One of the main risk factors of aggressive periodontitis is family history associated with inherited genetic traits. There is strong evidence that shows family history in young patients with early onset of aggressive periodontal disease ${ }^{(1)}$. Efforts made in the last twenty years to identify specific genetic variations involved in the disease have not been conclusive.

Regarding oral hygiene, studies have suggested that there would be no correlation between plaque levels and the presence of disease ${ }^{(1)}$.

Risk factors identified for periodontal diseases are similar to the ones for chronic periodontitis and aggressive periodontitis ${ }^{(28)}$. These factors include: immunological host factors, ethnicity, microbiological factors, oral hygiene habits, age, gender, frequency of dental visits, demographic factors, smoking habits and psychological factors ${ }^{(29)}$.

\section{Histopathology and immunopathology}

No major differences between aggressive and chronic periodontitis in terms of its histopathology and immunopathology are reported ${ }^{(1,2)}$. Both appear as plasma-cell dominated lesions and mediated by Th2 cells. The localized form of aggressive periodontitis may represent a different entity with a genetic or epigenetic component. This could explain the association with the family history. On the other hand, aggressive generalized periodontitis could represent an advanced chronic periodontitis in young people with extreme 
susceptibility, which would explain the common histopathological and immunopathological characteristics. These hypotheses need to be confirmed through rigorous studies ${ }^{(30)}$.

Localized aggressive periodontitis is frequently associated with deficiencies in the neutrophilic function and with high serum antibody response against periodontopathogens; while generalized aggressive periodontitis is also associated with deficiencies in neutrophil function, but with low serum antibody response against periodontopathogens ${ }^{(31)}$. Histopathological changes are reflected in the bone changes detected radiographically, even in mixed dentition ${ }^{(32)}$.

Furthermore, the colonization of the periodontal pocket by periodontal pathogenic bacteria could lead to an overlap of chronic periodontitis, which may complicate the histological and immunohistological condition ${ }^{(2)}$.

\section{Microbiology}

Some reports support the existence of subgingival microbiota resistant to antibiotics of choice $^{(33-40)}$, which could explain eventual failures in the therapeutic modality. Localized aggressive periodontitis is mainly associated with the bacteria Aggregatibacter actinomycetemcomitans ${ }^{(41,42)}$, while generalized aggressive periodontitis is strongly associated with specific bacteria such as Porphyromonas gingivalis, Tannerella forsythia ${ }^{(43,44)}$ and Aggregatibacter actinomycetemcomitans, Gram-negative coccobacillus, capnophile, microaerophilic ${ }^{(45)}$. Microorganisms produce several virulence factors that could be involved in the destruction of periodontal tissues. The most important one seems to be leukotoxic $\operatorname{activity}^{(46,47)}$. The highly leukotoxic bacterial strains of Aa (strain JP2) can produce 10 to 20 times more toxins than other strains, giving them the potential to interfere with innate immune host defenses ${ }^{(48)}$. Some studies have shown that highly leukotoxic strains appear exclusively in individuals or families with a history of aggressive periodontitis ${ }^{(49-51)}$.

\section{Clinical forms}

\subsection{Localized aggressive periodontitis}

It begins at peripubertal age. It is mainly located in the first molars/incisors, with interproximal attachment loss in at least two permanent teeth, one of which is a first molar, and which 
affects no more than two other teeth, apart from the first molars and incisors. It can also present atypical patterns, such as affecting other teeth instead of those mentioned.

\subsection{Generalized aggressive periodontitis}

It usually affects people under 30 , but they may be older. There is an interproximal attachment loss which affects at least three permanent teeth additional to the first molars and incisors. Attached gingiva tissue loss is episodic ${ }^{(31)}$.

\section{DIAGNOSIS}

\section{Evaluation of the systemic condition}

The patient's medical history should be thoroughly evaluated. We must determine if there are risk factors such as smoking and psychosocial stress ${ }^{(5)}$. Since one of the characteristics of aggressive periodontitis is the absence of systemic diseases ${ }^{(32)}$, complementary tests can be run, if necessary, to rule out background pathologies. Record if the patient is taking any medication. Inquire about family history regarding periodontal condition ${ }^{(4)}$

\section{Periodontal clinical examination}

The following should be evaluated: clinical attachment levels, periodontal pocket depth, bleeding on probing, furcations compromised, dental mobility, suppuration and oral hygiene.

\section{Radiological examination}

It is extremely important. The following are recommended:

- Periapical radiographic series: It should be done using the parallel technique and, preferably, a millimeter grid. There are the following options: seven radiographs for the upper arch and seven for the lower arch, two interproximal radiographs for molars and two for premolars.

- Radiovisiography: This is mainly indicated for cases of diagnostic doubt, regenerative therapy evaluation, periodontal status monitoring, among others. It is especially recommended for young patients with mixed dentition, where probing can be confusing. A distance greater than $2 \mathrm{~mm}$ between the cementoenamel junction and the alveolar crest in subjects with mixed dentition may suggest aggressive periodontitis. 


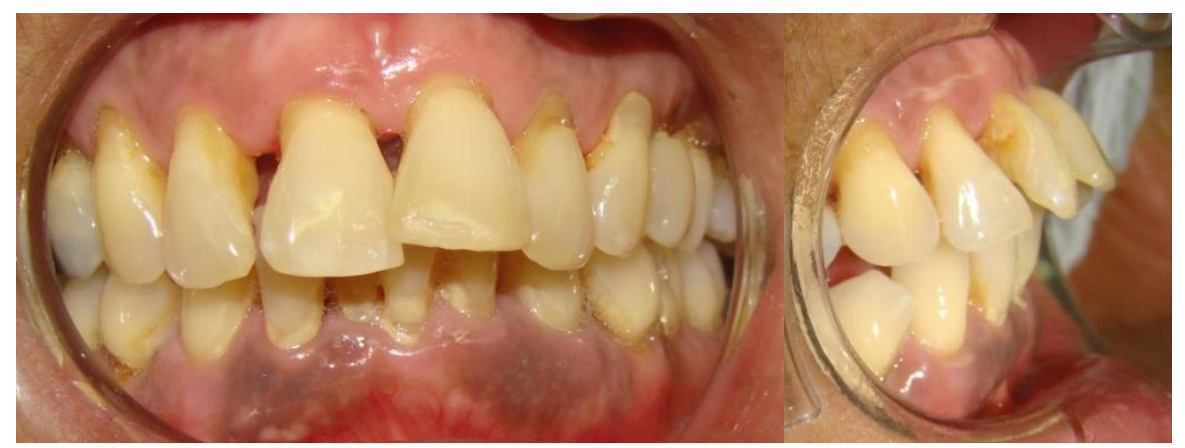

A

B

Figure 1. Clinical photograph of 56-year-old female patient old with aggressive periodontitis.
A. Front view
B. Side view.

\section{MANAGEMENT ACCORDING TO COMPLEXITY LEVEL AND RESOLUTION ABILITY}

Studies agree that treatment should be supplemented with antibiotics ${ }^{(53)}$. The objectives of the treatment are the same as for chronic periodontitis: reducing or eliminating the bacterial load and the contributory risk factors, in addition to regenerating the attachment apparatus as soon as possible.

\section{TREATMENT PLAN SEQUENCE FOR PATIENTS WITH AGgRESSIVE PERIODONTITIS}

\subsection{Systemic Phase}

- Medical referral, if indicated

- Medical interconsultation for the modulation of risk factors (tobacco, psychosocial stress)

\subsection{Initial Phase}

- Emergency treatment, if necessary

- Educating the patient about the disease process, contributing factors, perpetuating factors and triggers

- Teaching the patient about oral hygiene, evaluation and reinforcement of plaque control measures ${ }^{(4)}$ 
- Study, diagnosis and treatment of occlusal disharmony and temporomandibular disorders $^{(4)}$

- Taking bacterial samples from selected pockets, cultures and antibiotic sensitivity testing can also be considered ${ }^{(4)}$

- Prior dental treatments, if necessary

- Supragingival and subgingival scaling and root planing. Mechanical therapy is key in the treatment of aggressive periodontitis ${ }^{(4,53)}$. Even current consensus is that antimicrobial therapy should be preceded by mechanical debridement to break the structure of the biofilm ${ }^{(54)}$.

- Atraumatic extraction of non-viable teeth preserving the ridge.

- Local and systemic antibiotic treatment. The application of antibiotics via both pathways has advantages and limitations ${ }^{(54)}$.

\section{Systemic administration}

Prescribing systemic antibiotics for the treatment of aggressive periodontitis is properly supported $^{(37,38)}$. The combination of amoxicillin and metronidazole as an adjuvant is the best option, as described in recent systematic reviews ${ }^{(52,54-56)}$, especially for its effectiveness on Aggregatibacter actinomycetemcomitans ${ }^{(33)}$. Other recommended antibiotics for the treatment of aggressive periodontitis are metronidazole, spiramycin and clindamycin ${ }^{(34)}$. This method has the advantage of reaching all the areas of the oral cavity. However, optimal patient compliance is required to avoid an irregular administration that may not achieve the expected goals or may lead to bacterial resistance ${ }^{(54)}$.

\section{Local administration}

It allows for a high concentration of the drug in specific areas that would not be reached systemically; however, since not all the affected areas are treated, there may be reinfection $^{(54)}$. Several studies show that an adjuvant therapy with local antimicrobials leads to pocket depth reduction and significant increases in the clinical attachment level compared 
to the control groups. There is a better effect using tetracycline fibers, followed by doxycycline and minocycline. The application of chlorhexidine chips achieves minimal improvements in periodontal condition ${ }^{(54,57,58)}$.

\subsection{Re-evaluation}

- We should evaluate whether the treated sites show reduced probing depth, clinical attachment gain and resolution of inflammation. Oral hygiene and patient's motivation should also be evaluated(59), in addition to tooth mobility, occlusal state and root sensitivity.

- Samples can be taken from selected pockets, medical interconsultation can be implemented, if indicated, and additional laboratory tests can be requested, if applicable.

\subsection{Surgical Phase}

Studies show that access or regenerative surgical treatments may have good results in patients with aggressive periodontitis, and that the effect may be similar to the ones obtained in chronic periodontitis; provided it is complemented with proper oral hygiene, risk factors are controlled and a rigorous maintenance program is followed ${ }^{(60)}$.

Resective, reparative or regenerative treatments can be carried out depending on the case. In aggressive periodontitis, antimicrobial surgical and comprehensive mechanical therapy is an appropriate treatment protocol for long-term stabilization of periodontal health ${ }^{(53)}$.

If there is improvement after surgical treatment, maintenance will be carried out; otherwise, we should return to the initial phase. It is important to monitor the surgically-treated areas.

\subsection{Maintenance Phase}

The success of the treatment will largely depend on patient compliance, both through adherence to doctor's instructions and by attending clinic appointments ${ }^{(56)}$. Medical appointments every three months have shown favorable results; however, based on the patient's periodontal status, the frequency may vary ${ }^{(55)}$.

- Monitor probing depth, clinical attachment level, gingival bleeding, tooth mobility ${ }^{(55)}$, patient's oral hygiene and risk factors ${ }^{(60)}$ 
- Conduct annual radiographic examination of changes in the bone tissue of teeth at risk

- Perform scaling, root planing and polishing of residual pockets ${ }^{(55)}$

- Topical fluoridation treatment and root desensitization (if indicated)

- Assess the need to resume the local or systemic antibiotic treatment

- Occlusal adjustment and balancing by selective wear of premature contacts in centric relation with or without pathological displacements (if necessary)

- Consider extracting teeth with terminal or unviable progressive disease using conservative and regenerative techniques of the residual alveolar bone.
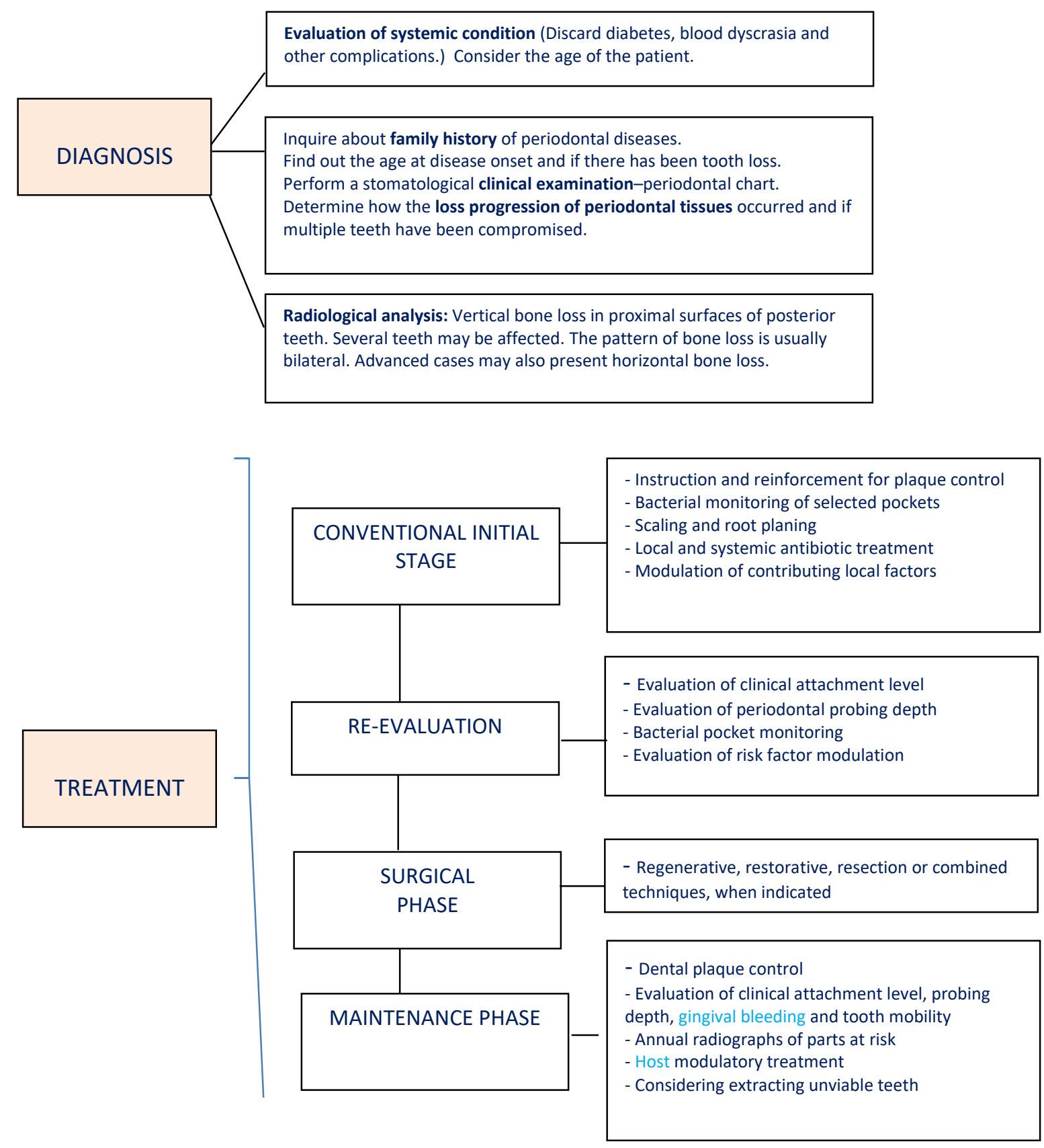
Figure 2. Aggressive periodontitis diagnosis criteria flowchart (based on Albandar (2014) $)^{(32)}$ and therapeutic routines for aggressive periodontitis

\section{EXPECTED RESULTS AFTER AGRESSIVE PERIODONTITIS TREATMENT:}

- Significant reduction of clinical signs of gingival inflammation

- Reduction of probing depths

- Stabilization or gain of clinical attachment

- Radiographic evidence of resolution of bone lesions

- Reduction of clinically detectable plaque to a level compatible with an adequate level of periodontal health

- Progress toward occlusal stability ${ }^{(4,31)}$

The $\mathrm{AAP}^{(4)}$ highlights the following considerations for these patients:

- Systemic evaluation of the patient to rule out diseases, hereditary traits and conditions that have periodontal repercussions

- The application of a mechanical treatment alone is usually not effective.

- The long-term treatment outcome will depend on the patient's care, compliance with maintenance appointments and plaque control skills. If primary teeth are affected, eruption of permanent teeth should be monitored to detect possible attachment loss.

- Due to the potential familial nature of aggressive diseases, evaluation and counseling of family members may be indicated ${ }^{(4)}$.

It is common to fail in the treatment of aggressive periodontitis due to certain virulence factors of $A$. actinomycetemcomitans and $P$. gingivalis, which cannot be properly removed, due to their cell and tissue penetration ability ${ }^{(36)}$.

\section{CONCLUSIONS}

Aggressive periodontitis are rare pathologies, mainly found in patients of African ethnicity or African descent. Early onset, family aggregation and rapid progression are usually their main characteristics. Consensus have been established on the forms of the disease: localized and 
generalized. Immunological, genetic and microbiological factors are strongly associated, and seem to determine the two presentation forms. The concept of exclusivity of the periodontal pathogen Aggregatibacter actinomycetemcomitans in aggressive periodontitis has been partially depreciated. Controversies have also arisen about the classification of aggressive periodontitis as a clinical entity independent from chronic periodontitis, because they share a common genetic basis, which would explain the phenotypic expression of the same disease. The diagnostic and therapeutic protocol does not differ much from that of other periodontal diseases; however special attention should be paid to family history, systemic condition, early diagnosis, specialized management by a periodontist, plaque control and frequent monitoring of periodontal pockets.

\section{REFERENCES}

1. Botero JE, Bedoya E. Determinantes del diagnóstico periodontal. Rev. Clin. Periodoncia Implantol Rehabil Oral [Internet] 2010; [Cited: 2016 Jun 13]; 3 (2): 94-99. Available from: http://www.scielo.cl/scielo.php?script=sci_arttext\&pid=S071901072010000200007\&lng=es.

2. Armitage GC, Cullinan MP. Comparison of the clinical features of chronic and aggressive periodontitis. Periodontol 2000. 2010; 53 (1): 12-27.

3. Armitage, GC. Development of a classification system for periodontal diseases and conditions. Ann. Periodontol.1999; 4 (1): 1-6.

4. American Academy of Periodontology. Parameters on aggressive periodontitis. J periodontol. 2000; 71 (5): 867-869.

5. Meng, H, Xu, L, Li Q, Han J, Zhao Y. Determinants of host susceptibility in aggressive periodontitis. Periodontol 2000. 2007; 43 (1): 133-159.

6. Carvalho RP, Mesquita JS, Bonomo A, Elsas PX, Colombo AP. Relationship of neutrophil phagocytosis and oxidative burst with the subgingival microbiota of generalized aggressive periodontitis. Oral Microbiol Immunol. 2009; 24 (2): 124-132.

7. Fine DH, Markowitz K, Furgang D, Fairlie K, Ferrandiz J, Nasri C, McKieran M, Gunsolley J. Aggregatibacter actinomycetemcomitans and its relationship to Initiation of localized 
aggressive periodontitis: Longitudinal cohort study of initially healthy adolescents. J Clin Microbiol. 2007; 45 (12): 3859-3869.

8. Faveri M, Mayer MP, Feres M, de Figueiredo LC, Dewhirst FE, Paster BJ. Microbiological diversity of generalized aggressive periodontitis by $16 \mathrm{~S}$ rRNA clonal analysis. Oral Microbiol Immunol. 2008; 23 (2): 112-118.

9. Armitage GC, Cullinan MP, Seymour GJ. Comparative biology of chronic and aggressive periodontitis: Introduction. Periodontol 2000. 2010; 53(1): 7-11. doi:10.1111/j.16000757.2010.00359.x.

10. Kinane DF, Hart TC. Genes and gene polymorphisms associated with periodontal disease. Crit Rev Oral Biol Med. 2003; 14 (6): 430-49.

11. Kantarci A, Oyaizu K, Van Dyke TE. Neutrophilmediated tissue injury in periodontal disease pathogenesis: Findings from localized aggressive periodontitis. J Periodontol. 2003; 74 (1): 66-75.

12. Srinivas M, Chethana KC, Padma R, Suragimath G, Anil M, Pai BS. Walvekar A. A study to assess and compare the peripheral blood neutrophil chemotaxis in smokers and non smokers with healthy periodontium, gingivitis, and chronic periodontitis. J. Indian Soc. Periodontol. [Internet] 2012. [Cited: 2016 May 10]; 16 (1): 54-58. Available from: http://doi.org/10.4103/0972-124X.94605.

13. Barbieri Petrelli G, Flores Guillén J, Vignoletti F. El neutrófilo y su importancia en la enfermedad periodontal. Av Periodon Implantol. 2005; 17 (1): 11-16.

14. Daniel MA, McDonald G, Offenbacher S, Van Dyke TE. Defective chemotaxis and calcium response in localized juvenile periodontitis neutrophils. J Periodontol.1993; 64 (7): 617-621.

15. Shibata K, Warbington ML, Gordon BJ, Kurihara H, Van Dyke TE. Defective calcium influx factor activity in neutrophils from patients with localized juvenile periodontitis. J Periodontol. 2000; 71 (5): 797-802. 
16. Kurihara $\mathrm{H}$, Murayama $\mathrm{Y}$, Warbington ML, Champagne CM, Van Dyke TE. Calciumdependent proteinkinase $\mathrm{C}$ activity of neutrophils in localized juvenile periodontitis. Infect Immun.1993; 61 (8): 3137-3142.

17. Albandar JM, Tinoco EM. Global epidemiology of periodontal diseases in children and young persons. Periodontol 2000. 2002; 29 (1): 153-76.

18. Albandar JM, Rams TE. Risk factors for periodontitis in children and young persons. Periodontol 2000. 2002; 29 (1): 207-22.

19. Lopez R, Baelum V. Classifying periodontitis among adolescents: Implications for epidemiological research. Community Dent Oral Epidemiol. 2003; 31 (2): 136-43.

20. Pérez Luzardo Benigna. Periodontitis agresiva: Clasificación, características clínicas y etiopatogenia. Acta odontol venez [Internet] 2009; 47 (5): 135-160. Cited: 2016 Jun 26. Available from: $\quad$ http://www.scielo.org.ve/scielo.php?script=sci_arttext\&pid=S0001$63652009000300020 \& \operatorname{lng}=e s$.

21. Allin N, Cruz-Almeida Y, Velsko I, Vovk A, Hovemcamp N, Harrison P, Huang H, Aukhil I, Wallet SM, Shaddox LM. Inflammatory Response Influences Treatment of Localized Aggressive Periodontitis. J Dent Res 2016; 95 (6): 635-41. doi: 10.1177/0022034516631973. 22. Albandar JM, Brown LJ, Löe H. Clinical features of early-onset periodontitis. J Am Dent Assoc 1997; 128 (10): 393-1399.

23. Löe H, Brown LJ. Early onset periodontitis in the United States of America. J Periodontol $1991 ; 62$ (10): 608-616.

24. Kissa J, Chemlali S, El Houari B, Amine K, Khlil N, Mikou S. et al. Aggressive and chronic periodontitis in a population of Moroccan school students. J Clin Periodontol. 2016; 43 (11): 934-939. doi: 10.1111/jcpe.12584.

25. Arowojolu MO, Nwokorie CU. Juvenile periodontitis in Ibadan, Nigeria. East Afr Med J. $1997 ; 74(6): 372-375$

26. Albandar JM, Muranga MB, Rams TE. Prevalence of aggressive periodontitis in school attendees in Uganda. J Clin Periodontol. 2002; 29 (9): 823-831. 
27. Hodge PJ, Teague PW, Wright AF, Kinane DF. Clinical and genetic analysis of a large North European Caucasian family affected by early onset periodontitis. J Dent Res. 2000; 79 (3): 857-863.

28. Stabholz A, Soskolne WA, Shapira L. Genetic and environmental risk factors for chronic periodontitis and aggressive periodontitis. Periodontology 2000. 2010; 53 (1): 138-153.

29. Noack B, Hoffmann T. Aggressive periodontitis. Perio. 2004; 1 (4): 335-344.

30. Smith M, Seymour GJ, Cullinan MP. Histopathological features of chronic and aggressive periodontitis. Periodontology 2000. 2010; 53 (1): 45-54.

31. Discepoli N, Bascones-Martínez A. Controversias etiológicas, diagnósticas y terapéuticas de la periodontitis agresiva. Av Periodon Implantol. 2008; 20 (1): 39-47.

32. Albandar J. Aggressive periodontitis: case definition and diagnostic criteria. Periodontol 2000. 2014; 65(1): 13-26.

33. Guerrero A, Griffiths GS, Nibali L, Suvan J, Moles DR, Laurell L, Tonetti MS. Adjunctive benefits of systemic amoxicillin and metronidazole in non-surgical treatment of generalized aggressive periodontitis: a randomized placebo-controlled clinical trial. J Clin Periodontol. 2005; 32 (10): 1096-1107.

34. B. Sigusch, M. Beier, G. Klinger, W. Pfister, E. Glockmann. A 2-Step Non-Surgical Procedure and Systemic Antibiotics in the Treatment of Rapidly Progressive Periodontitis. J Periodontol. 2001; 72 (3): 275-283. doi: 10.1902/jop.2001.72.3.275.

35. Deas DE, Mealey BL. Response of chronic and aggressive periodontitis to treatment. Periodontol 2000. 2012; 53 (1): 154-166.

36. Collins JR, Arredondo A, Roa A, Valdez Y, León R, Blanc V. Periodontal pathogens and tetracycline resistance genes in subgingival biofilm of periodontally healthy and diseased Dominican adults. Clin Oral Investig [Internet] 2016; 20 (2): 349-356. Cited: 2016 Jun 14. Available from: http://doi.org/10.1007/s00784-015-1516-2.

37. Haffajee AD, Socransky SS, Gunsolley JC. Systemic anti-infective periodontal therapy. A systematic review. Ann Periodontol. 2003; 8 (1): 115-181. 
38. Herrera D, Sanz M, Jepsen S, Needleman I, Roldan S. A systematic review on the effect of systemic antimicrobials as an adjunct to scaling and root planing in periodontitis patients. $\mathrm{J}$ Clin Periodontol. 2002; 29 (3): 136-159.

39. Listgarten MA, Lai $\mathrm{CH}$, Young V. Microbial composition and pattern of antibiotic resistance in subgingival microbial samples from patients with refractory periodontitis. $\mathrm{J}$ Periodontol.1993; 64 (3): 155-161.

40. Mejia GI, Botero A, Rojas W, Robledo JA. Refractory periodontitis in a Colombian population: Predominant anaerobic bacterial flora and antibiotic susceptibility. Clin Infect Dis. 1995; 20 (2): 311-313.

41. Faveri M, Figueiredo LS, Duarte PM, Mestnik MJ, Mayer MP, Feres M. Microbiological profile of untreated subjects with localized aggressive periodontitis. J Clin Periodontol. 2009; 36 (9): 739-49. doi: 10.1111/j.1600-051X.2009.01449.x.

42. Cortelli JR, Cortelli SC, Jordan S, Haraszthy VI, Zambon JJ. Prevalence of periodontal pathogens in Brazilians with aggressive or chronic periodontitis. J Clin Periodontol. 2005; 32 (8): 860-6.

43. Könönen E, Müller HP. Microbiology of aggressive periodontitis. Periodontol 2000. 2014; 65 (1): 46-78. doi: 10.1111/prd.12016.

44. Souza Silveira VR, Bessa Nogueira MV, Pinto Nogueira NA, Lima V, Chaves Furlaneto FA, Otavio Rego R. Leukotoxicity of Aggregatibacter actinomycetemcomitans in generalized aggressive periodontitis in Brazilians and their family members. Journal of Applied Oral Science [Internet] 2013; 21 (5): 430-436. Cited: 2016 May 18. Available from: http://doi.org/10.1590/1679-775720130252.

45. Fine DH, Kaplan JB, Kachlany SC, Schreiner HC. How we got attached to Actinobacillus actinomycetemcomitans: a model for infectious diseases. Periodontol 2000. 2006; 42 (1): 114-57.

46. Contreras A, Rusitanonta T, Chen C, Wagner WG, Michalowicz BS, Slots J. Frequency of 530-bp deletion in actinobacillus actinomycetemcomitans leukotoxin promoter region. Oral Microbiol Immunol. 2000; 15 (5): 338-40. 
47. Lourenço TG, Heller D, do Souto RM, Silva-Senem MX, Varela VM, Torres MC, Colombo AP. Long-term evaluation of the antimicrobial susceptibility and microbial profile of subgingival biofilms in individuals with aggressive periodontitis. Braz J Microbiol [Internet] 2015; 46 (2): 493-500. Cited: 2016 Apr 6. Available from: http://doi.org/10.1590/S1517838246220131037.

48. Brogan JM, Lally ET, Poulsen K, Kilian M, Demuth DR. Regulation of Actinobacillus actinomycetemcomitans leukotoxin expression:analysis of the promoter regions of leukotoxic and minimally leukotoxic strains. Infect Immun. 1994; 62 (2): 501-8.

49. Bueno LC, Mayer MP, DiRienzo JM. Relationship between conversion of localized juvenile periodontitis-susceptible children from health to disease and Actinobacillus actinomycetemcomitans leukotoxin promoter structure. J Periodontol.1998; 69 (9): 998-1007. 50. Haraszthy VI, Hariharan G, Tinoco EM, Cortelli JR, Lally ET, Davis E, et al. Evidence for the role of highly leukotoxic Actinobacillus actinomycetemcomitans in the pathogenesis of localized juvenile and other forms of early-onset periodontitis. J Periodontol. 2000; 71 (6): 912-22.

51- Haubek D, Ennibi OK, Poulsen K, Poulsen S, Benzarti N, Kilian M. Early-onset periodontitis in Morocco is associated with the highly leukotoxic clone of Actinobacillus actinomycetemcomitans. J Dent Res. 2001; 80 (6): 1580-3.

52. Xajigeorgiou C, Sakellari D, Slini T, Baka A, Konstantinidis A. Clinical and microbiological effects of different antimicrobials on generalized aggressive periodontitis. $\mathrm{J}$ Clin Periodontol. 2006; 33 (4): 254-264.

53. Buchmann R, Nunn ME, Van Dyke TE, Lange DE. Aggressive periodontitis: 5-year follow-up of treatment. J Periodontol. 2002; 73 (6): 675-683.

54. Jepsen, K. and Jepsen, S. Antibiotics/antimicrobials: systemic and local administration in the therapy of mild to moderately advanced periodontitis. Periodontol 2000. 2016; 71 (1): 82 112. doi: $10.1111 /$ prd.12121.

55. American Academy of Periodontology. Parameter on Periodontal Maintenance. J Periodontol. 2000; 71 (5): 849-850. 
56. Rabelo CC, Feres M, Gonçalves C, Figueiredo LC, Faveri M, Tu Y-K, Chambrone L. Systemic antibiotics in the treatment of aggressive periodontitis. A systematic review and a Bayesian Network meta-analysis. J Clin Periodontol. 2015; 42 (7): 647-657.

57.Matesanz-Pérez P, García-Gargallo M, Figuero E, Bascones-Martínez A, Sanz M, Herrera D. A systematic review on the effects of local antimicrobials as adjuncts to subgingival debridement, compared with subgingival debridement alone, in the treatment of chronic periodontitis. J Clin Periodontol. 2013; 40 (3): 227-241.

58. Garcia Canas P, Khouly I, Sanz J, Loomer PM. Effectiveness of systemic antimicrobial therapy in combination with scaling and root planing in the treatment of periodontitis: a systematic review. J Am Dent Assoc. 2015; 146 (3): 150-63. doi:10.1016/j.adaj.2014.12.015. 59. Bouziane A, Benrachadi L, Abouqal R, Ennibi O. Outcomes of nonsurgical periodontal therapy in severe generalized aggressive periodontitis. J Periodontal Implant Sci. 2014; 44 (4): 201-206. doi.org/10.5051/jpis.2014.44.4.201.

60.Teughels W, Dhondt R, Dekeyser C, Quirynen M. Treatment of aggressive periodontitis. Periodontol 2000. 2014; 65 (1): 107-133. doi: 10.1111/prd.12020.

María Pareja: mariapareja-@hotmail.com 